\title{
Surgical Pathology Procedure
}

National Cancer Institute

\section{Source}

National Cancer Institute. Surgical Pathology Procedure. NCI Thesaurus. Code C128792.

A laboratory procedure that involves the examination of surgical resection or biopsy tissue samples for diagnostic or research purposes. 